\title{
OS MANUAIS DO PROFESSOR COMO FONTE DE PESQUISA ${ }^{1}$
}

\section{The teacher's handbooks as source of research}

\author{
André Luiz Paulilo*
}

\begin{abstract}
RESUMO
Este artigo tem como finalidade apresentar resultados de uma pesquisa acerca do ensino de História. Este estudo busca mostrar os manuais do professor como fonte de pesquisa. Trata-se de discussão fundamentada na ideia de que, no Brasil, os manuais do professor trazem representações acerca do ensino. Argumenta-se que os paradigmas organizadores do discurso sobre as práticas de ensino nos manuais didáticos têm composto bases teóricas e metodológicas específicas. Assim, o artigo expõe e analisa alguns aspectos desse tipo de impresso.
\end{abstract}

Palavras-chave: ensino de História; manuais do professor; Ensino Fundamental; representações.

\begin{abstract}
This article aims to present research findings on the teaching of history. We intend to show the teacher's handbooks as source of research. It is related to a discussion based on the idea that, in Brazil, the teacher's handbooks bring the representations about the teaching. It is inferred that the organizer paradigm of the discourse about the practice of the teaching in handbooks have composed specific basis. In addition, the paper display and analyzes some aspects of this printed one.
\end{abstract}

Keywords: teaching of History; teacher's handbooks; Education Elementary; representations.

Parte suplementar que acompanha o exemplar do professor do livro didático, o Manual do Professor oferece orientação teórico-metodológica

\footnotetext{
"Universidade Estadual de Campinas.

1 Esta pesquisa contou com financiamento do CNPq.
} 
específica ao docente para a utilização da obra na sala de aula. Trata-se de uma exigência do edital de inscrição no processo de avaliação para o PNLD, que reconhece nesse tipo de texto um recurso para o esclarecimento das propostas do livro didático. Nesse sentido, o Manual do Professor não é somente um aspecto da edição. Sobretudo, atende as prescrições do poder público quanto à acepção e à organização dos dispositivos dos textos que lhe devem caracterizar. Indissociáveis uma da outra, as dimensões editorial e política desses manuais suscitam questões que, já bastante exploradas por estudos sobre os livros do aluno, enredam o texto, o livro e as suas estratégias simbólicas.

As análises de Alain Choppin (2000) sobre os aspectos formais dos manuais didáticos, de Anne-Marie Chartier (2007) a respeito dos papéis prescritivos que os textos oficiais e o cotidiano da profissão docente exercem nesse âmbito e de Michael Apple (1995) acerca dos efeitos do atual estágio do consumo de material didático pelas escolas têm indicado caminhos fecundos de pesquisa. ${ }^{2}$ No que se refere aos livros didáticos de história do aluno, Bittencourt (1993), Munakata (1997) e Gatti Jr. (1998) já publicaram estudos bem-sucedidos nesses âmbitos de análise. ${ }^{3}$ As perspectivas então abertas à abordagem dos aspectos formais, dos conteúdos e pedagogias e das políticas de aquisição, edição e distribuição desse tipo de obra mostram que há dispositivos textuais de produção e apresentação do conhecimento indissociáveis da forma como o livro circula e das práticas que ele enseja.

Algumas novas pesquisas têm reivindicado outras possibilidades de investigação. A recepção e o uso dos livros didáticos em sala de aula são temas atualmente bastante explorados. Matela (1994), Costa (1997), Araújo (2001), Cassiano (2003) e Bittencourt (2004) avaliam que as interferências

2 CHOPPIN, A. Pasado y presente de los manuales escolares. In: BERRIO, J. L. (Org.). La cultura escolar de Europa: tendencias históricas emergentes. Madrid: Editorial Biblioteca Nueva, 2000, p. 107-141; CHARTIER, A.-M. Práticas de leitura e escrita: história e atualidade. Belo Horizonte: Autêntica, 2007; e APPLE, M. W. Trabalho docente e textos: economia das relações de classe e de gênero em educação. Porto Alegre: Artes Médicas, 1995.

3 BITTENCOURT, C. Livro didático e conhecimento histórico: uma história do saber escolar. Tese (Doutorado) - Faculdade de Filosofia, Letras e Ciências Humanas da Universidade de São Paulo. São Paulo, 1993; MUNAKATA, K. Produzindo livros didáticos e paradidáticos. Tese (Doutorado) - Programa de Estudos Pós-Graduados em Educação: História, Política, Sociedade da PUC-SP. São Paulo, 1997; e GATTI JR., D. Livros didáticos e ensino de História: dos anos sessenta aos nossos dias. Tese (Doutorado) - Programa de Estudos Pós-Graduados em Educação: História, Política, Sociedade da PUC-SP. São Paulo, 1998. 
de professores e alunos fazem parte da compreensão do livro didático. ${ }^{4}$ Principalmente, nessas pesquisas pergunta-se sobre como o público-alvo desse tipo de publicação utiliza os conteúdos, os instrumentos de aprendizagem, a ideologia e os valores neles contidos. ${ }^{5}$

Os resultados acumulados por esses estudos permitem ter uma compreensão já bastante assentada a respeito dos processos de produção do livro didático de História e dos conhecimentos que ele veicula. Conforme levantamento elaborado por Kênia Hilda Moreira (2006), existem análises sobre o discurso veiculado pelo livro didático, seus conteúdos expressos e os meios de sua edição, cujas principais conclusões testemunham a profusão de usos e problemáticas suscitados desse recurso de ensino. ${ }^{6}$ Principalmente as investigações acerca das práticas e dos significados que se operam a partir do uso do livro didático de História permitem interrogar a substância e o conteúdo da história ensinada. Seus resultados de pesquisa mostram-se úteis ao chamar a atenção para o fato da história local, do cotidiano e de outras populações que não as europeias ganharem importância na crítica de uma disciplina escolar ainda em grande parte dominada pelo modelo histórico eurocêntrico, economicista e voltado para a formação do Estado-nação.

Embora todas essas prevenções também sejam pertinentes para uma abordagem dos métodos de aprendizagem da disciplina que os livros didáticos incluem, as questões que os manuais do professor melhor possibilitam propor são outras. Dirigido ao docente, esse tipo de texto tem a finalidade de expor a concepção de aprendizagem que o livro do aluno

4 MATELA, R. C. P. O professor de história e o livro didático: uma relação delicada. Dissertação (Mestrado) - Educação. Universidade Federal Fluminense. Niterói, 1994; COSTA, A. M. S. Prática pedagógica e tempo escolar: o livro didático no ensino de História. Dissertação (Mestrado) Programa de Estudos Pós-Graduados em Educação: História, Política, Sociedade da PUC-SP. São Paulo, 1997; ARAÚJO, L. T. O uso do livro didático no ensino de História: depoimentos de professores de escolas estaduais de ensino fundamental situadas em São Paulo. Dissertação (Mestrado) - Programa de Estudos Pós-Graduados em Educação: História, Política, Sociedade da PUC-SP. São Paulo, 2001; CASSIANO, C.C.F. Circulação do livro didático: entre práticas e prescrições - políticas públicas, editoras, escolas e o professor na seleção do livro escolar. Dissertação (Mestrado) - Programa de Estudos Pós-Graduados em Educação: História, Política, Sociedade da PUC-SP. São Paulo, 2003; e BITTENCOURT, C. M. F. Ensino de História: fundamentos e métodos. São Paulo: Cortez, 2004. (Coleção Docência em Formação: série Ensino Fundamental).

5 Cf. BITTENCOURT, C. M. F. Ensino de História: fundamentos e métodos, op. cit., p. 302.

6 MOREIRA, K. H. Um mapeamento das pesquisas sobre o livro didático de história na região sudeste: 1980 a 2000. Dissertação (Mestrado) - Programa de Pós Graduação em Educação Escolar; Faculdade de Ciências e Letras da UNESP. Araraquara, 2006. 
contém. De onde a ênfase dada às abordagens metodológicas, às instruções operacionais, aos meios e materiais do ensino de História que organizam representações, categorias intelectuais e formas retóricas em orientações de trabalho. Os manuais do professor não são apenas marcados por um protocolo de leitura, eles testemunham também a presença de uma importante discussão didática sobre o ensino de História, que visa teorizar as modalidades de aprendizagem, preconiza o trabalho com fontes e propõe uma nova cultura da participação.

Assim, o Manual do Professor atualmente não é apenas uma referência pedagógica para o ensino, mas principalmente designa o lugar de um discurso sobre a prática do ensino. Nesse âmbito, parece razoável interrogar sua força ilocutória, as estratégias que propõe e a ordem de representações que instaura, seja para discutir as escolhas de seus autores ou para inventariar as demandas dirigidas ao professor de História ultimamente. Mais que as opções didáticas e metodológicas expressas no Manual do Professor dos livros didáticos de História, as justificativas das quais seus autores se valem indicam as modalidades de aprendizagem, os recursos e a maneira de ensinar a matéria já socialmente compartilhada, considerada legítima. Trata-se de pistas para se compreender algo das relações que o Manual do Professor mantém com as práticas de aula.

De circulação pouco vista fora dos percursos da sua distribuição nas escolas, os manuais respondem à ideia de que é necessário pôr em ação instrumentos que possam contribuir para a contínua atualização do professor. Nesses termos, atentar para os discursos que o Manual do Professor veicula nos pareceu ser um recurso para pensar os atuais processos de construção da Didática da História. No que se segue, a preocupação com as representações que esse tipo de publicação faz do ensino de História e da prática docente resultou num estudo dos dispositivos do seu agenciamento discursivo e de algumas das categorias que os fundam. Sobretudo porque os manuais do professor fornecem indícios sobre as práticas educativas que eles próprios prescrevem, achamos que seria uma boa ideia abordar os modelos de ensino e aprendizagem da História a partir dos procedimentos recomendados nesse tipo de publicação. Por essa razão, em vez de interrogar os docentes sobre as suas práticas e as pressões a que são submetidos em sua vida profissional, priorizamos a análise das estratégias de que esses manuais são o produto. Contra as formulações abruptas provenientes dos levantamentos estatísticos 
ou do inventário das aparelhagens mentais, o esforço de pesquisa seguiu outro caminho.

Partimos da análise do Manual do Professor dos livros didáticos de História recomendados no Guia do PNLD-2008 para identificar "com o quê" e "como" ele pretende instrumentalizar o professor para ensinar a matéria. Trata-se de dimensionar os discursos que põem em ação e as regras que limitam a sua produção. Assim, debruçamo-nos sobre as marcas dos usos prescritos e dos destinatários visados nesse tipo de impresso com vistas a apurar que práticas fomentam, quais denunciam e como interpelam o docente de História. Essa abordagem favorece a obtenção de indícios sobre os métodos pedagógicos usuais, sobre critérios de seleção de conteúdos, sobre os pressupostos teóricos que orientam as iniciativas de ensino e sobre as políticas de formação continuada de professores. No entanto, os resultados desse procedimento não deixam de ter limites e restrições. Por meio da atenção ao instituído pela escrita consegue-se muito pouco sobre os usos que são feitos do Manual do Professor. Vem de Certeau (1994) a advertência de que

[...] diante de uma produção racionalizada, expansionista, centralizada, espetacular e barulhenta se posta uma produção de tipo totalmente diverso, qualificada como "consumo", que tem como característica suas astúcias, seu esfarelamento em conformidade com as ocasiões, suas piratarias, sua clandestinidade, seu murmúrio incansável, em suma, uma quase-invisibilidade, pois ela quase não se faz notar por produtos próprios, mas por uma arte de utilizar aqueles que lhe são impostos. ${ }^{7}$

Portanto, não convém perder de vista que as pessoas adaptam o sistema de objetos e de significados às próprias necessidades. Por outro lado, antes de investigar os usos feitos pelo magistério do Manual do Professor, pensamos que cumpre entender melhor esse tipo de material que lhe chega às mãos.

7 CERTEAU, M. de. A invenção do cotidiano. v. 1 - Artes de fazer. Petrópolis: Vozes, 1994, p. 94 . 


\section{Uma tipificação}

Quando em 1996 determinou-se que a aquisição de obras didáticas com verbas públicas para distribuição em território nacional estaria sujeita à inscrição e avaliação prévias, segundo regras estipuladas em edital próprio $^{8}$, o setor editorial brasileiro foi estabelecendo fortes dependências em relação aos critérios de avaliação estipulados por meio do PNLD. Conforme os mecanismos que Luca e Miranda (2004) explicitam ao analisar os processos de avaliação dos livros de História destinados ao segmento de 5. ${ }^{\mathrm{a}}$ à 8. ${ }^{a}$ séries de 1999, 2002 e 2005, "o fato de uma obra não estar presente no Guia publicado pelo MEC traz efeitos financeiros indesejáveis que, em alguns casos, culminaram no desaparecimento de editoras e/ou em fusões de grupos editoriais". ${ }^{9}$ Assim, não só os princípios gerais da área e os critérios eliminatórios publicados pelo Edital ditam as condições e as especificações para inscrição no processo de avaliação e seleção das coleções didáticas, como também indicam os critérios de qualificação da coleção e os objetivos da área no ensino fundamental. Entre todos esses ditames, há indicações específicas para a produção dos manuais do professor que, desse modo, importam destacar.

Desde a implantação do atual sistema de avaliação das coleções didáticas pelo MEC/FNDE em 1999, é vedado que o exemplar do professor seja uma cópia do livro do aluno com exercícios resolvidos. No Edital do PNLD-2008, a exigência é que ele "ofereça orientação teórico-metodológica e de articulação dos conteúdos do livro entre si e com outras áreas do conhecimento; ofereça, também, discussão sobre a proposta de avaliação da aprendizagem, leituras e informações adicionais ao livro do aluno, bibliografia, bem como sugestões de leitura que contribua para a formação e atualização do professor". Insiste-se ainda que as orientações ao professor tenham coerência com a apresentação dos conteúdos e com as atividades propostas no livro do aluno. A concepção de meio de atualização e de auxiliar do uso do livro didático na sala de aula que aparece no edital tipifica o Manual do Professor como instrumento complementar do trabalho docente.

8 LUCA, T. R.; MIRANDA, S. R. O livro didático de história hoje: um panorama a partir do PNLD. Revista Brasileira de História, São Paulo, v. 24, n. 48, p. 123-144, 2004, p. 127.

9 Idem. 
Igualmente, o Guia de Livros Didáticos PNLD-2008: História concebe e avalia o Manual do Professor como um impresso de orientação e apoio ao magistério. A avaliação que traz publicada sob a forma de resenha dos livros então recomendados inclui comentários circunstanciados sobre o Manual do Professor de cada coleção. Em seu conjunto, mais que instituir os fundamentos e os objetivos desse impresso, o Guia qualifica os tipos de manuais e as discussões que sustentam. Trata-se da análise das 19 coleções recomendadas, agrupadas em quatro blocos, segundo a organização dos conteúdos:

organização temática

(a proposta da coleção é organizada por temas)

\begin{tabular}{|c|c|c|c|c|c|c|}
\hline $\begin{array}{l}\text { Có- } \\
\text { digo }\end{array}$ & Série & Editora & Autores & Ano & $\begin{array}{l}\text { pá- } \\
\text { ginas }\end{array}$ & Unidades \\
\hline 012 & $\begin{array}{l}\text { Série Link do } \\
\text { tempo: História }\end{array}$ & $\begin{array}{l}\text { Escala Educa- } \\
\text { cional }\end{array}$ & $\begin{array}{l}\text { Denise Mattos Marino } \\
\text { Léo Stampacchio }\end{array}$ & & 154 & 4 módulos \\
\hline 061 & $\begin{array}{l}\text { História por eixos } \\
\text { temáticos }\end{array}$ & Editora FTD & $\begin{array}{l}\text { Antônio Pedro } \\
\text { Lizânias de Souza Lima }\end{array}$ & 2006 & 270 & 8 eixos \\
\hline 104 & História temática & Scipione & $\begin{array}{l}\text { Andréa R. Dias Montellato } \\
\text { Conceição Aparecida Cabrini } \\
\text { Roberto Catelli Jr. }\end{array}$ & & 238 & 4 eixos \\
\hline 105 & $\begin{array}{l}\text { Historiar - fa- } \\
\text { zendo, contando } \\
\text { e narrando a His- } \\
\text { tória }\end{array}$ & Scipione & Dora Schmidt & & 222 & 2 a 4 cap. \\
\hline
\end{tabular}

organização integrada

(História do Brasil, da América e Geral, seguindo ou não a ordem do estabelecimento das sociedades. Para a integração destas histórias, é imprescindível que se estabeleçam relações contextualizadas entre os conteúdos tratados, considerando a simultaneidade dos acontecimentos no tempo e no espaço)

\begin{tabular}{c|l|l|l|l|l|l}
\hline $\begin{array}{r}\text { Có- } \\
\text { digo }\end{array}$ & Série & Editora & Autores & Ano & $\begin{array}{l}\text { pági- } \\
\text { nas }\end{array}$ & \begin{tabular}{l} 
Unidades \\
\hline 013
\end{tabular} \\
$\begin{array}{l}\text { Por dentro da } \\
\text { História }\end{array}$ & $\begin{array}{l}\text { Escala Educa- } \\
\text { cional }\end{array}$ & $\begin{array}{l}\text { Célia Regina Cerqueira Vicentino } \\
\text { Maria Aparecida Cosomano } \\
\text { Pedro Santiago }\end{array}$ & 280 & 3 a 4 unid. \\
\hline 033 & $\begin{array}{l}\text { História em } \\
\text { projetos }\end{array}$ & Ática & $\begin{array}{l}\text { Andréa Paula } \\
\text { Carla Miucci Ferraresi } \\
\text { Conceição de Oliveira }\end{array}$ & 2006 & 272 & 3 a 5 unid. \\
\hline 075 & $\begin{array}{l}\text { Projeto Araribá-- } \\
\text { História }\end{array}$ & Moderna & Editora Moderna & 238 & $\begin{array}{l}8 \text { unida- } \\
\text { des }\end{array}$ \\
\hline
\end{tabular}




\begin{tabular}{|c|c|c|c|c|c|c|}
\hline 076 & $\begin{array}{l}\text { História: das } \\
\text { cavernas ao } \\
\text { terceiro milênio }\end{array}$ & Moderna & $\begin{array}{l}\text { Myrian Becho Mota } \\
\text { Patrícia Ramos Braick }\end{array}$ & & 298 & $\begin{array}{l}4 \text { unida- } \\
\text { des }\end{array}$ \\
\hline 088 & $\begin{array}{l}\text { Diálogos com a } \\
\text { História }\end{array}$ & Positivo & $\begin{array}{l}\text { Kátia Corrêia Peixoto Alves } \\
\text { Regina Gomido Belisário }\end{array}$ & 2006 & 220 & $\begin{array}{l}4 \text { unida- } \\
\text { des }\end{array}$ \\
\hline 140 & $\begin{array}{l}\text { Navegando pela } \\
\text { História }\end{array}$ & $\begin{array}{l}\text { Quinteto } \\
\text { Editorial }\end{array}$ & $\begin{array}{l}\text { Maria Luiza Vaz } \\
\text { Silvia Panazzo }\end{array}$ & & 186 & 4 a 5 unid. \\
\hline 151 & $\begin{array}{l}\text { História: con- } \\
\text { ceitos e procedi- } \\
\text { mentos }\end{array}$ & Saraiva & $\begin{array}{l}\text { Eliete Toledo } \\
\text { Ricardo Dreguer }\end{array}$ & & 172 & $\begin{array}{l}4 \text { unida- } \\
\text { des }\end{array}$ \\
\hline
\end{tabular}

organização intercalada

(ordena a História do Brasil e da América junto com a Geral, normalmente em ordem cronológica crescente, mas os conteúdos não são relacionados entre estas histórias, apenas os assuntos são alternados nos espaços em que ocorreram, conforme a seqüência temporal)

\begin{tabular}{|c|c|c|c|c|c|c|}
\hline $\begin{array}{l}\text { Có- } \\
\text { digo }\end{array}$ & Série & Editora & Autores & Ano & Pág. & Unidades \\
\hline 029 & $\begin{array}{l}\text { História e vida } \\
\text { integrada }\end{array}$ & Ática & $\begin{array}{l}\text { Claudino Piletti } \\
\text { Nelson Piletti }\end{array}$ & & 242 & 21 a 24 cap. \\
\hline 032 & História Hoje & Ática & Oldimar Pontes Cardoso & & 290 & 23 a 24 cap. \\
\hline 060 & $\begin{array}{l}\text { História em } \\
\text { documento: } \\
\text { imagem e texto }\end{array}$ & FTD & Joelza Ester Rodrigue & & 300 & 4 a 5 unid. \\
\hline 062 & $\begin{array}{l}\text { História, socieda- } \\
\text { de e cidadania }\end{array}$ & FTD & Alfredo Boulos Júnior & & 258 & 17 a 21 cap. \\
\hline 089 & $\begin{array}{l}\text { Encontros com a } \\
\text { História }\end{array}$ & Positivo & $\begin{array}{l}\text { Carla Maria Junho Anastasia } \\
\text { Vanise Maria Ribeiro }\end{array}$ & & 260 & 3 a 4 unid. \\
\hline 103 & $\begin{array}{l}\text { Construindo } \\
\text { consciências - } \\
\text { História } \\
\end{array}$ & Scipione & Leonel Itaussu de Almeida Mello & & 250 & 18 a 19 cap. \\
\hline 152 & $\begin{array}{l}\text { Saber e fazer } \\
\text { História }\end{array}$ & Saraiva & Gilberto Cotrim & & 200 & 12 a 17 cap. \\
\hline
\end{tabular}


organização convencional

(A organização dos conteúdos é feita a partir da 5 . $^{\mathrm{a}}$ série em História do Brasil, Colônia e Império, e na 6. ${ }^{a}$ série com a Primeira República até a redemocratização; na 7. a série, começa com História Geral, incluindo

Pré-História, Antiguidade e Medieval, e, na 8. ${ }^{a}$ série, estuda-se Moderna e Contemporânea)

\begin{tabular}{l|l|l|l|l|l|l}
\hline Código & Série & Editora & Autores & Ano & Pág. & Unidades \\
\hline 030 & $\begin{array}{l}\text { Descobrindo } \\
\text { a história }\end{array}$ & Ática & $\begin{array}{l}\text { Sônia Maria Mozer } \\
\text { Vera Lúcia Pereira Telles Nunes }\end{array}$ & 2006 & 288 & 21 a 32 cap. \\
\hline
\end{tabular}

Como no Edital, no Guia de Livros Didáticos PNLD-2008: História insiste-se que o Manual do Professor precisa ser considerado um instrumento pedagógico auxiliar da prática docente e sugerir leituras e outros recursos para a atualização do professor. No entanto, é mais específico na maneira de fazê-lo, indicando que avaliou as informações adicionais ao Livro do Aluno e a forma de orientar a execução das atividades e objetivos propostos e buscou identificar as propostas e discussões sobre avaliação da aprendizagem e sugestões de atividades e de leitura para os alunos.

Uma conclusão geral expressa no Guia diz respeito à heterogeneidade dos elementos contemplados pelos manuais do professor das coleções então recomendadas. Bastante diversos entre si, nem sempre os manuais tratam todos os quesitos que a Comissão de Avaliação considerou necessários. Um simples levantamento panorâmico dos aspectos destacados nas considerações publicadas no Guia de Livros Didáticos PNLD-2008: História já mostra o que melhor qualifica o Manual do Professor. Invariavelmente, sugestões de procedimentos, propostas metodológicas, bibliografia atualizada, comentários adicionais de conteúdo e de atividades, listas de livros e textos de apoio, orientações no uso de recursos didáticos e considerações sobre a metodologia de ensino, quando aparecem, são registrados e abordados. Na prática, o Guia constitui o Manual do Professor como o lugar da discussão em torno dos pressupostos históricos da coleção, da organização didática da aula que se propõe, das fontes, escritas, iconográficas ou orais, e da avaliação do processo de ensino e aprendizagem.

É possível constatar a irregularidade indicada pelo Guia de Livros Didáticos PNLD-2008: História quanto aos quesitos tratados nos manuais do professor das coleções didáticas na própria definição que os livros didá- 
ticos têm desse suplemento. Das 19 séries recomendadas pelo PNLD-2008, nove apresentam uma designação alternativa à de Manual do Professor. Nas coleções que evitam utilizar a expressão "manual", os títulos dessa parte do exemplar do professor variam sob as fórmulas de Caderno de Orientações Pedagógicas, de Manual Pedagógico, de Livro do Professor, de Orientações ao Professor, de Assessoria Pedagógica, de Guia e Recursos Didáticos, Suplemento do Professor ou de Apoio Didático. Nesses casos, o domínio das ideias de orientação, assessoria, apoio didático e guia demonstra algo das pretensões didáticas da coleção. Em parte, tais ideias observam o propósito de fazer do Manual do Professor mais do que uma formalidade editorial. Por outro lado, afirma-se o valor de meio de atualização e de auxiliar do uso do livro didático na sala de aula que o Edital e o Guia do PNLD-2008 conferem a esse recurso.

Também variam de uma coleção para outra os agenciamentos do texto, as suas formas tipográficas e a diagramação. Com uma editoração invariavelmente feita em duas cores, as seções que organizam os textos dos manuais do professor das diversas coleções não são sempre as mesmas. A ênfase nos procedimentos didáticos em algumas das coleções, o foco na fundamentação histórica em outras e a insistência com que outra parte dos manuais sublinha o perfil psicológico da faixa etária e da metodologia a ser adotada para o desenvolvimento do conteúdo de História confirmam a heterogeneidade das abordagens e dos dispositivos que propõem a leitura das instruções. As orientações para a resolução dos exercícios ou atividades propostas no livro do aluno estão em todas as séries.

A despeito das diferenças de acento e enfoque, há outros protocolos de leitura que são observados por todas as coleções recomendadas pelo PNLD-2008. De partida, são discutidos os pressupostos teóricos da coleção, sua fundamentação metodológica e sua linha historiográfica. Após, as orientações dos autores tratam dos procedimentos de trabalho propostos na coleção e da organização didática dos conteúdos, dos temas ou da ordem dos capítulos. Por um lado, expõe-se a metodologia de ensino desenvolvida pela coleção, os seus princípios pedagógicos, seu modo de trabalhar e de fazer trabalhar com as fontes e as estratégias explicativa e de investigação adotadas. De outro, ficam explícitas, por meio de considerações gerais sobre os propósitos da edição do livro didático, as questões de estruturação da coleção como objetivos, sequência e encadeamento das unidades e icono- 
grafia. Depois disso, uma proposta de avaliação é apresentada e justificada. Seguem-se seções com sugestões de material didático suplementar, geralmente filmes, músicas e sítios da internet e de bibliografia complementar de ensino para o professor.

Conforme solicitado em Edital, avaliado pelo Guia de Livros Didáticos PNLD-2008: História e assumido por seus autores, o Manual do Professor deve incentivar a autonomia do docente na prática educativa. É visto como um recurso tanto para explicitar a proposta pedagógica e a concepção de história que a coleção comporta quanto para sugerir atividades e procedimentos de avaliação. Tido como instrumento de apoio relevante no exercício do magistério porque coloca em cena a proposta de um trabalho educativo cotidiano, o Manual do Professor, sobretudo, é parte da oferta pedagógica de um autor e da oferta comercial de um editor de livros didáticos. ${ }^{10}$ No entanto, para interrogar o valor de uso desse tipo de impresso talvez seja mais útil ter em conta a forma da escolha e a maneira como se faz a sua distribuição. A regulamentação estabelecida pelo edital e o processo de escolha do professor, principalmente, suscitam questões acerca das relações que docentes e governo mantêm com as prioridades didáticas dos atuais métodos do ensino de História. Em muitos sentidos, os vínculos entre o poder público e o mercado da edição escolar fazem pensar a conjuntura que age sobre os guias de trabalho dos livros didáticos quando se trata do valor de uso do Manual do Professor, das orientações dos seus autores ou mesmo da divulgação das editoras.

\section{Editoras, governo e professores}

Segundo o entendimento que Anne-Marie Chartier tem dos livros didáticos, a sua elaboração é guiada pela combinação de pressões conjunturais e das orientações dos autores. Trata-se da edição de um material escolar que tanto apresenta um conjunto de saberes quanto ordena um repertório de exercícios de acordo com o público visado e as prescrições vigentes para o 
ensino. Assim, conforme argumenta Chartier, os autores de manuais não só devem levar em consideração os programas e textos oficiais, como também o cotidiano da profissão docente. Essa argumentação acompanha as seguintes linhas. Os manuais didáticos evoluem em função dos programas, mas não somente em decorrência desse fator: "a edição escolar forjou hábitos de trabalho, dispositivos didáticos, expectativas e exigências que os professores colocam em prática". A conjuntura age tanto em favor das rupturas como em favor das continuidades. Tanto a chegada de pesquisadores especialistas ao campo da edição escolar e a mudança dos objetivos do ensino fundamental "estão modificando o processo de criação dos livros didáticos" quanto as inquietações com uma eficácia imediata dos métodos de ensino fazem "os editores repetirem as fórmulas já experimentadas, que sabem que funcionam e nas quais os professores confiam". As orientações dos autores participam do espaço da invenção ou da perpetuação das tradições, uma vez que "na criação de um livro didático, estão envolvidos a cultura da pesquisa científica do autor, seus valores pedagógicos e políticos, suas preferências culturais e estéticas, sua experiência com crianças e com a aprendizagem escolar, sua hierarquia das prioridades e urgências, quando se trata de textos para ler ou das escolhas de exercício". ${ }^{11}$

No caso do Manual do Professor, esses aspectos estão ainda mais evidentes, pois o autor, em alguma medida, escreve sobre eles. A referência aos Parâmetros Curriculares Nacionais e a historiografia citada nas coleções, as propostas de planejamento do curso, as indicações sobre material didático complementar e o discurso que o autor produz sobre o método empregado permitem abordar as respostas que se costumam dar às prescrições do programa e às pressões da realidade profissional da docência. Ao proporem estratégias de aula, princípios de legitimação dos objetos de estudo, normas de cientificidade e modos de avaliação, os autores dos manuais para professor decodificam os procedimentos metodológicos do ensino. Daí a pertinência de se perguntar como o fazem. Desde o tipo de organização e encaminhamento pedagógico que propõe para o ensino de História até o inventário de meios e recursos do trabalho em sala, o Manual do Professor opera escolhas, guia conteúdos, uma progressão, exercícios e modalidades de avaliação. Por essa razão, pensar os modos de articulação 
que esse tipo de texto mantém com as práticas sobre as quais orienta não só é uma maneira de considerar o sentido que produzem, como também de compreender o "horizonte de expectativa" do público a que se dirige. ${ }^{12}$

A combinação de fatores da qual trata Anne-Marie Chartier adverte que os modelos de ensino se inscrevem nas formas institucionais da escola e do mercado quando pensados em função dos seus suportes materiais. $\mathrm{O}$ recurso às fórmulas já experimentadas, conferindo-se prioridade àquilo que já é clássico em um livro didático, contribui não só para dar feição às antecipações do leitor em relação ao texto, mas para angariar novos públicos ou usos inéditos. Em tese, o docente dispõe do Manual do Professor como um suplemento em formato $205 \mathrm{~mm}$ x $275 \mathrm{~mm}$ editado em duas cores e cujo argumento invariavelmente compreende os pressupostos teóricos da coleção, a metodologia de ensino então desenvolvida, os objetivos, a sequência e o encadeamento das unidades, uma proposta de avaliação, sugestões de material didático complementar e orientações para a resolução dos exercícios ou atividades propostas no livro do aluno. Na prática, porém, sem se saber o perfil dos professores que utilizam o Manual ou mesmo se de fato o leem e o usam no preparo das suas aulas, a análise do efeito produzido no ensino da matéria fica restrita a um inventário de possibilidades. Mais uma vez aqui, o acúmulo de pesquisa sobre o livro do aluno deve sinalizar as principais vias de abordagem.

Neste terreno de trabalho em que se enredam texto e leitor, várias proposições já foram articuladas de maneira a mostrar os usos que os professores fazem do livro didático. Em comum, há o reconhecimento de que o conhecimento contido nos livros depende da forma pela qual o professor o faz chegar aos alunos. Nas atuais pesquisas sobre livro didático, está assentado que ele pressupõe uma leitura que necessita da intermediação do professor. Ao tratar dessa questão, Circe Bittencourt (2004) conclui que a utilização do livro didático pelos professores é muito diversa. Não obstante muitas das pesquisas ainda insistirem que toda a ideologia desse tipo de material é incorporada por alunos e professores sem mediação alguma, a autora adverte que a recepção feita pelos usuários é variada, "até porque o público escolar não é constituído por um grupo social homogêneo". ${ }^{13}$ Nesse 
mesmo âmbito, Luciana Telles de Araújo (2001) mostrou que geralmente as obras didáticas servem para complementar as explicações dos professores e que um número considerável de professores apenas faz uso dos exercícios e atividades propostas pelo livro do aluno. Outro recurso amplamente utilizado, segundo Araújo, nas obras didáticas pelos professores são as imagens cuja compilação feita nos livros permite os alunos refletirem sobre as representações que lhes são "postas diante dos olhos". ${ }^{14}$ Noutra perspectiva, Célia Cristina Cassiano (2004) apresenta dados de pesquisa que lhe permitiram entender como aspectos da materialidade dos livros didáticos interferem na prática pedagógica do professor. Sobretudo, ela mostra que muitas vezes esses livros atuam como "um constrangimento que obriga o professor a reelaborar o desenvolvimento de sua prática", muito em função do material distribuído pelo PNLD, e mesmo que chegam a alterar os saberes pedagógicos que circulam na sala de aula. ${ }^{15}$

O emprego de entrevistas e questionários nessas pesquisas tem permitido entender como se dão a escolha e o uso do livro didático entre os professores. Algumas das conclusões dos estudos de Araújo e Cassiano autorizam aproximações com os manuais do professor. Por um lado, a constatação de que é bastante comum o uso do livro didático na preparação das aulas e no planejamento escolar sugere que a leitura do Manual do Professor talvez seja também uma prática auxiliar efetiva. Em todo caso, parece-nos útil ter em conta as ponderações de Araújo sobre a variabilidade do grau de dependência dos professores em relação ao material didático. De acordo com as suas conclusões, essa é uma questão associada à formação e às condições de trabalho do professor, sobretudo à quantidade de escolas e horas de aula semanais. Por outro lado, a distância que o professor mantém do uso prescrito pelos formuladores do material didático tem sido mais bem qualificada. Cassiano mostrou que os professores da sua amostra ignoraram o Guia de Livros Didáticos porque preferem fazer suas escolhas com o livro na mão. Araújo traz o exemplo de um professor que dizia adotar o livro didático apenas para utilizar as ilustrações. Em muitas das entrevistas compiladas por Araújo e Cassiano, o livro didático aparece como um ponto

14 ARAÚJO, L.T. Op. cit., p. 73.

15 CASSIANO, C. C. Aspectos políticos e econômicos da circulação do livro didático de História e suas implicações curriculares. História, v. 23, n. 1-2, p. 47, 2004. 
de apoio para a organização das aulas, servindo como matriz e como "meio de recordar" temas pouco vistos na licenciatura. Para Gimeno Sacristán, a apropriação efetiva do livro pelos professores é tão criativa quanto capaz de acomodar o uso dos materiais didáticos a "um uso correto a partir de pressupostos da democracia cultural, atualização científica e pedagógica". ${ }^{16}$

Nesse âmbito de considerações, a pertinência do Manual do Professor por vezes é discutida noutros termos. Nas recomendações que Antônio Augusto Gomes Batista fez ao MEC em estudo encomendado pela Secretaria de Educação Fundamental do Ministério, além de contribuir para a atualização do magistério, o Manual do Professor deveria ter a função de orientar uma utilização correta do livro didático. ${ }^{17}$ Em sentido absolutamente contrário às conclusões dos estudos sobre o uso que os docentes fazem dos livros didáticos, ver no Manual do Professor apenas um meio de referir o uso mais apropriado desse tipo de material escolar reduz as possibilidades de compreensão das estratégias de ordenamento das questões pedagógicas nas coleções didáticas. Superar essa perspectiva de análise implica considerar os esquemas geradores de classificação e de percepção articulados pelo suplemento de orientação didática. Roger Chartier postula pensar as relações que mantêm as produções discursivas e as práticas sociais para se inscrever "a compreensão dos diversos enunciados que modelam as realidades no seio das restrições objetivas que limitam e tornam possível, ao mesmo tempo, sua enunciação". ${ }^{18}$ Sobretudo, trata-se de levar em conta não só as estratégias por meio das quais autores e editores tentam impor uma ortodoxia do texto, uma leitura forçosa, mas, igualmente, a liberdade dos leitores.

Sob a perspectiva das possibilidades de leitura, Kazumi Munakata mostrou haver no livro didático toda uma maquinaria singular que postula a desnecessidade do professor. A Munakata parece que as reiteradas solicitações dirigidas ao leitor-aluno para formar grupos de discussão, procurar

16 GIMENO SACRISTÁN, J. Materiales y textos: contradicciones de la democracia cultural. In: GARCÍA MÍNGUES, J.; BEAS MIRANDA, M. (Org.). Libro de texto y construcción de materiales curriculares. Granada: Proyecto Sur, s.d. p. 110.

17 BATISTA, A. A. G. Recomendações para uma política pública de livros didáticos. Brasília: MEC, Secretaria de Educação Fundamental, 2001.

18 CHARTIER, R. À beira da falésia: a história entre certezas e inquietude. Porto Alegre: Editora da Universidade/UFRGS, 2002. p. 119. 
professores de outras disciplinas, realizar entrevistas com pessoas de um determinado período resultam de um modelo de ensino que pretende reduzir a possibilidade do professor escapar das orientações então propostas no livro didático. ${ }^{19}$ Segundo conclui, quanto mais protocolos de leitura contiver um livro, mais desnecessária é a autonomia do professor. O Manual do Professor, no entanto, pressupõe o docente, mas, igualmente, apresenta dispositivos de condicionamento do uso do livro didático. Alguns deles, explícitos, recorrem ao discurso na forma de nota, carta ou apresentação. Outros dispositivos estão implícitos nos comentários sobre o trabalho desenvolvido em cada unidade do livro, nas indicações complementares de material e num conjunto de estratégias editoriais para impor uma justa compreensão do material, como no caso dos títulos, das caixas de texto e dos ícones. Cotejar assim o Manual do Professor com o livro do aluno não só dá ensejo para uma verificação da coerência entre a proposta aplicada no texto didático e enunciada no suplemento docente, entre o conhecimento escolar posto à disposição para os alunos e as possibilidades pedagógicas sugeridas ao professor. Com essa aproximação, abre-se uma via de análise que, principalmente, permite considerar as coleções didáticas como uma forma institucionalizada e objetivada em virtude da qual certos agentes dotam de eficácia uma disciplina, uma ordem ou representação do ensino.

A questão posta pelo desencontro entre a estratégia dos autores, das editoras e do governo e a apropriação efetiva do livro pelos professores é a das posições e propriedades sociais objetivas, exteriores ao discurso, que caracterizam os diferentes grupos, comunidades ou classes que constituem o mundo social. Na dinâmica de análise elaborada por Roger Chartier para articular a construção discursiva do mundo social à construção social dos discursos, há uma importante contribuição para a abordagem desse traço das atuais condutas e ações de ensino. Fundamentalmente, Chartier tem mostrado que as apropriações concretas e as inventivas dos leitores dependem, em seu conjunto, dos efeitos de sentido das obras, dos usos e dos significados impostos pelas formas de sua publicação e circulação, e das competências e expectativas que regem a relação que cada grupo mantém com a cultura

19 MUNAKATA, K. O livro didático e o professor: entre a ortodoxia e a apropriação. In: MONTEIRO, A. M.; GASPARELlO, A. M.; MAGALHÃES, M. S. (Org.). Ensino de história: sujeitos, saberes e práticas. Rio de Janeiro: Mauad X, 2007. p. 143. 
escrita. ${ }^{20}$ Nesses termos, os recursos materiais, a cultura científica, a experiência pedagógica de que dispõem os docentes e os autores de material escolar são tão constitutivos do social quanto os princípios que organizam os seus discursos. A ligação estabelecida por Chartier entre as construções discursivas e as propriedades sociais objetivas designa com alguma precisão a possibilidade de um trabalho sobre práticas que visam fazer reconhecer uma maneira específica de proceder.

\section{O discurso competente sobre o ensino de História}

Para a compreensão dos dispositivos do objeto tipográfico que propõe um texto à leitura, Chartier confere uma importância central ao "processo pelo qual um texto, uma fórmula, uma norma fazem sentido para os que deles se apoderam ou os recebem". ${ }^{21}$ Contra uma definição puramente semântica do texto, enfatiza a materialidade do objeto impresso. Essa perspectiva recusa ver, à maneira das formas mais radicais da "virada linguística" (linguistic turn), as práticas constitutivas do social reduzidas aos princípios que organizam os discursos. Conforme explica Chartier, "a prática discursiva é uma prática específica que não reduz todos os outros regimes de prática a suas estratégias, suas regularidades e suas razões". ${ }^{22}$ Assim, a construção dos interesses que se dá por meio dos discursos não é apenas vista como determinada e limitada pelos recursos materiais e pelos utensílios intelectuais de que dispõem os agentes. Chartier, sobretudo, tem mostrado que os dispositivos materiais e formais pelos quais os textos atingem os leitores constituem um recurso essencial para se conhecer a maneira como os agentes sociais outorgam sentido às suas práticas e aos seus enunciados.

20 CHARTIER, R. L'histoire aujourd'hui: doutes, défis, propositions. Texto apresentado em conferência realizada no Instituto de Estudos Avançados - USP, em setembro de 1993; O mundo como representação. Estudos Avançados, v. 11, n. 5, p. 173-191, 1991; e representações. Lisboa: Difel, 1990. A história cultural: entre práticas

21 CHARTIER, R. O mundo como representação, op. cit., p. 181.

22 CHARTIER, R. À beira da falésia: a história entre certezas e inquietude, op. cit., p. 132. 
Essa ênfase da análise nos suportes materiais da produção e da circulação dos impressos e na materialidade das práticas e usos da leitura vem tornando indispensável, também ao estudo das edições didáticas, a abordagem de dois conjuntos de dispositivos. Ainda conforme mostrou Roger Chartier, por um lado, há os dispositivos que provêm das estratégias de escrita e das intenções do autor e, por outro, os que resultam de uma decisão do editor ou de uma exigência da oficina de impressão. ${ }^{23}$ Ambos os conjuntos atraíram a atenção de pesquisadores do livro didático no país e reúnem reflexões acerca dos processos materiais de circulação e apropriação desse tipo de publicação. Principalmente Munakata, Gatti Jr. e Cassiano se debruçaram sobre o papel e o perfil dos editores de livros didáticos de História brasileiros e do mercado editorial. Suas investigações tanto contribuem para o entendimento dos efeitos da industrialização dos processos de edição do livro escolar como advertem a respeito dos condicionantes que são a realidade do mercado consumidor e a concorrência com conglomerados editoriais de capital estrangeiro. ${ }^{24}$ Já o tratamento que, entre outros, Bittencourt, Davies, Gatti Jr. e Munakata dão aos discursos veiculados pelo livro didático faz perceber as marcas dos usos prescritos para os destinatários visados. ${ }^{25}$ Os padrões linguísticos e as formas de comunicação específicas que o autor e os técnicos especializados dos processos gráficos criam ao elaborar esses textos são estudados como indícios que nos capacitam entender o papel que o livro didático desempenha na vida escolar.

23 CHARTIER, R. O mundo como representação, op. cit., p. 182.

24 Ver principalmente MUNAKATA, K. Produzindo livros didáticos e paradidáticos, op. cit.; GATTI JR., D. Estado e editoras privadas no Brasil: o papel e o perfil dos editores de livros didáticos (1970-1990). Cadernos Cedes, Campinas, v. 25, n. 67, p. 365-377, set./dez. 2005 e CASSIANO, C. C. F. O mercado do livro didático no Brasil: da criação do Programa Nacional do Livro Didático à entrada do capital internacional espanhol - 1985-2007. Tese (Doutorado) - Programa de Estudos Pós-Graduados em Educação: História, Política, Sociedade da PUC-SP. São Paulo: 2007.

25 Sobretudo em BITTENCOURT, C. Livros didáticos entre textos e imagens. In: (Org.). O saber histórico na sala de aula. São Paulo: Contexto, 1997. (Coleção Repensando e Ensino) e Livro didático e conhecimento histórico: uma história do saber escolar. Tese (Doutorado) - Faculdade de Filosofia, Letras e Ciências Humanas da Universidade de São Paulo. São Paulo, 1993; DAVIES, N. Livro didático: apoio ao professor ou vilão do ensino de História. In: ENCONTRO PERSPECTIVAS DO ENSINO DE HISTÓRIA, 2, 1996, São Paulo. Anais... São Paulo: FEUSP, 1996, p. 600-604, GATTI JR., D. A escrita escolar da história: livro didático e ensino no Brasil (1970-1990). Bauru; Uberlândia: Edusc; Edufu, 2004; e MUNAKATA, K. O livro didático e o professor: entre a ortodoxia e a apropriação. In: MONTEIRO, A. M.; GASPARELLO, A. M.; MAGALHÃES, M. S. (Org.). Ensino de História: sujeitos, saberes e práticas. Rio de Janeiro: Mauad X, 2007. p. 137-148. 
Portanto, a ênfase é útil para pensar o Manual do Professor como meio de veiculação de técnicas de aprendizagem, sugestões de trabalho, exercícios e tarefas que os alunos devem desempenhar para a apreensão dos conteúdos. A reflexão sobre os suportes materiais da produção e da circulação dos impressos e na materialidade das práticas e usos da leitura põe em evidência dispositivos de imposição de saberes e normatização de práticas referidos a lugares de poder determinados. Na estruturação e nas condições de ensino que esses manuais visam elaborar para os professores perpassa uma relação de autoridade que tem muito a ver com as posições e as propriedades sociais objetivas de autores, docentes e alunos. Com efeito, para ser editado e encontrar seu lugar no mercado, um livro didático depende do crédito outorgado pelo Estado e/ou pelos professores ao que propõe como método de ensino. As pesquisas mostram que as pressões editoriais existem não só em função do regime jurídico que regulamenta a difusão, mas nas ideias e valores em que se inspiram e na suposta eficácia nos meios de ação propostos. ${ }^{26}$ Desde aqueles que participam do trabalho técnico ou pedagógico de edição e o autor até a comissão de especialistas avaliadores do PNLD, todo um sistema de qualificação é constituído para apurar a relevância do livro didático - cujo Manual do Professor atualmente é parte indispensável - para o currículo efetivo das escolas. Torres e Munakata entendem que o atual processo de avaliação e exclusão das coleções didáticas não apenas repousa na concepção de um texto programado, fechado, normativo, que orienta passo a passo o ensino, reduzindo a possibilidade de seleção do professor. ${ }^{27}$ Em muitos sentidos, os textos que se propõem organizar e prescrever como os conteúdos devem ser ensinados são também meios através dos quais grupos de profissionais tendem a persuadir o docente de que o ensino ou o exercício do magistério é, de fato, o que lhes dizem ser.

Ainda que o docente adote os livros mal avaliados ou use os livros didáticos de forma muito autônoma, procedendo de modo "que nem o autor, nem o editor, nem os formuladores das atividades, nem os avaliadores do

26 Cf. CHARTIER, A.-M., op. cit., p. 75.

27 TORRES, R. M. Melhorar a qualidade da educação básica? As estratégias do Banco Mundial. In: TOMMASI, L.; WARDE, M. J.; HADDAD, S. (Org.). O Banco Mundial e as politicas educacionais. 2. ed. São Paulo: Cortez, 1998, p. 157, e MUNAKATA, K. O livro didático e o professor: entre a ortodoxia e a apropriação, op. cit., p.144. 
PNLD imaginaram"28, o Manual do Professor contém um sistema didático construído e uma compreensão de ensino úteis para a pesquisa do como ensinar. Trata-se de esquemas de percepção e de apreciação do magistério, logo, das representações constitutivas de muito daquilo que foi interiorizado por aqueles que exercem a docência e que é exposto como evidência compartilhada. Segundo entende Anne-Marie Chartier, esse tipo de discussão é, basicamente, sobre os processos por meio dos quais se investem conceitos e objetivos dos produtores dos manuais escolares e onde se estabelecem as regras de escrita próprias ao gênero didático. ${ }^{29} \mathrm{O}$ objeto fundamental de uma análise que, assim, se propõe reconhecer a maneira pela qual as obras didáticas articulam competências, normas, usos e performances parece-me estar na tensão que há entre, por um lado, a oferta pedagógica de um manual de ensino e, por outro, a demanda por uma guia de trabalho.

Não obstante a relativa autonomia com que os professores fazem chegar o conhecimento aos alunos, ocorre que o valor de uso do suplemento docente é justificado pelas qualidades técnicas e influência do método dos títulos publicados. Como observa Anne-Marie Chartier, é certo que sem ser ratificado pela profissão em sala de aula não é possível reeditar regularmente uma obra didática. No entanto, a suposta eficácia dos meios de ação propugnados pelo Manual do Professor tem sido afirmada por meio de artifícios mediadores e promotores de conhecimento que constrangem o professor a se submeter à linguagem do especialista. A indicação da comissão de avaliação do PNLD, as instrumentalizações que o livro permite, a observância das novas demandas educacionais e as credenciais acadêmicas dos autores conferem prestígio ao conhecimento veiculado pelo livro didático. $\mathrm{Na}$ forma como esses protocolos operam sentido no Manual do Professor, as referências ao lugar de onde o autor se pronuncia e a legitimidade do que escreveu marcam a distância entre quem escreve sobre a prática e os docentes que procuram dar sentido prático a uma certa "razão escolástica" ${ }^{30}$

As informações que os livros de História recomendados no Guia de Livros Didáticos PNLD-2008 reúnem sobre os autores dizem respeito

28 MUNAKATA, K. O livro didático e o professor: entre a ortodoxia e a apropriação, op. cit., p. 144.

29 CHARTIER, A.-M., op. cit., p. 70.

30 Cf. BOURDIEU, P. Razões práticas: sobre a teoria da ação. Campinas: Papirus, 1997. 
as suas credenciais de competência. Sobretudo, dão conta da titulação e da atuação profissional dos autores das coleções. Essas referências adiantam ao leitor o lugar social em que se posicionam os autores de livros didáticos, indicando as funções que ocupam e as instituições a partir das quais se enunciam. A sistematização disso permite identificar quem está escrevendo as obras didáticas e em quais circunstâncias o tem feito.

No conjunto de 38 autores, há uma nítida predominância de bacharéis e licenciados pelos cursos de História da Universidade de São Paulo e da Pontifícia Universidade Católica de São Paulo. São 18 ocorrências de autores com essa formação, $47 \%$ do total dos autores das coleções e $90 \%$ dos autores que declaram sua formação inicial nos livros didáticos. Também predominam os autores com titulação obtida nos programas de pós-graduação dessas universidades. Há o registro de 14 mestrados e de 11 doutorados realizados na USP e/ou na PUC-SP. Entretanto, nesses níveis de especialização, nem sempre a titulação do autor é em História. Nelson Piletti e Oldimar Cardoso fizeram seus estudos de mestrado e doutorado em Educação na USP, Denise Mattos Marino é mestre em Educação pela Universidade Católica de Santos e Gilberto Cotrim pelo Mackenzie. Claudino Piletti e Joelza Ester Rodrigue possuem doutoramento em Educação pela USP e Alfredo Boulus Júnior pela PUC-SP. Em História, Andréa Paula e Maria Luísa Vaz realizaram seus mestrados e doutoramentos na USP, Alfredo Boulus Júnior, Lisânias de Souza Lima e Fabio Duarte Joly possuem mestrado pela USP e Joelza Ester Rodrigue, Léo Stampacchio e Vitória Rodrigues e Silva pela PUC-SP.

Embora as diversificações nesse quadro mostrem haver outros percursos de formação, não escapam da lógica de legitimação verificada na apresentação dos autores presente nas coleções didáticas. Assim, a presença de autores egressos dos cursos de História da UFMG, da licenciatura da Faculdade de Ciências Humanas de Itabira e de Ciências Sociais da própria USP entre os livros indicados pelo PNLD-2008 de História exprime a mesma linguagem institucionalmente articulada aos signos da competência universitária. Mais ainda, a recomendação de autores formados nos programas de pós-graduação em Ciências Sociais, Ciências Políticas, Comunicação e Direito da USP e da PUC-SP ou em História da Unicamp, da PUC-MG e da PUC-RS reforçam essas credenciais. Ao todo são 26 os autores de livros didáticos de História recomendados pelo PNLD-2008 que 
GRÁFICO 1 - ÁREAS DE FORMAÇÃO DOS PROFESSORES AUTORES DOS LIVROS DIDÁTICOS.

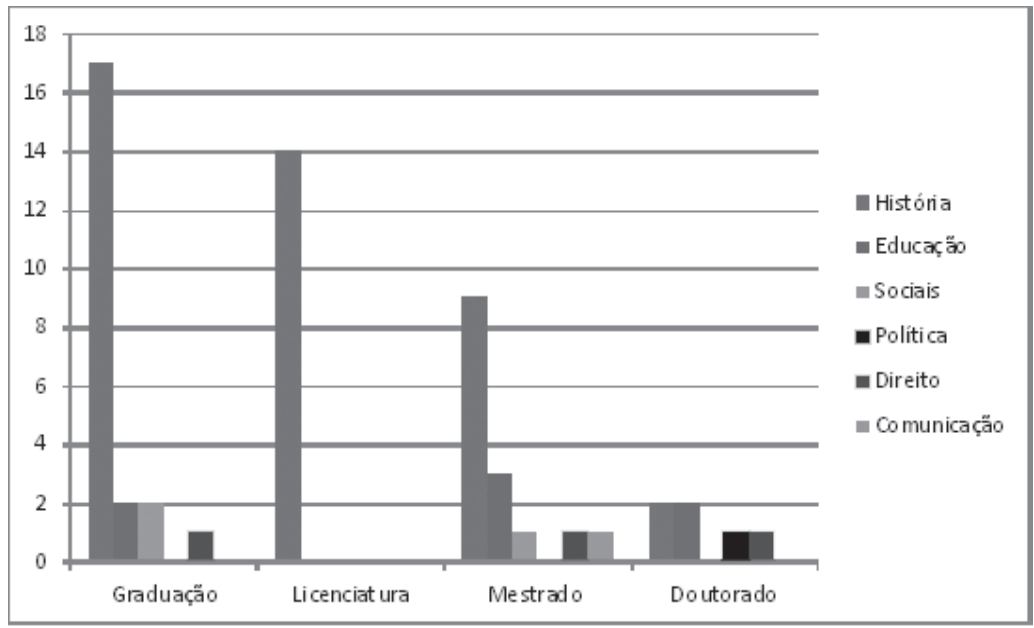

indicam ter concluído estudos de pós-graduação, cerca de $68 \%$ do total. Mais homogênea é a origem regional dessas produções, inteiramente concentrada nas regiões Sul e Sudeste. Não há referências institucionais fora do eixo São Paulo (30), Minas Gerais (5), Paraná (2) e Rio Grande do Sul (1). Esse predomínio coincide com a concentração em São Paulo de 7 das 8 editoras de livros didáticos recomendadas pelo Guia de Livros Didáticos PNLD-2008: História.

Quanto à atuação profissional, as referências ao exercício da docência na educação básica são um quesito sempre indicado. Essa indicação é utilizada por 22 dos autores, quase $58 \%$ dos casos. Apesar de mostrar experiência em sala de aula, ela é complementar aos outros apontamentos de atividade profissional ou titulação. Sem maiores especificações sobre o enquadramento funcional na carreira e se permanece em exercício, a informação apenas registra uma passagem pela profissão que é a daqueles a quem se dirigem no Manual do Professor. Não é o que ocorre com as indicações acerca da docência no ensino superior, realizada por 10 dos autores, quase $1 / 3$ do conjunto. Geralmente, dá-se conta da instituição e disciplina, o que permite perceber algo da dispersão profissional dos autores que vêm 
GRÁFICO 2 - REFERÊNCIAS DE LOCALIDADE DOS AUTORES.

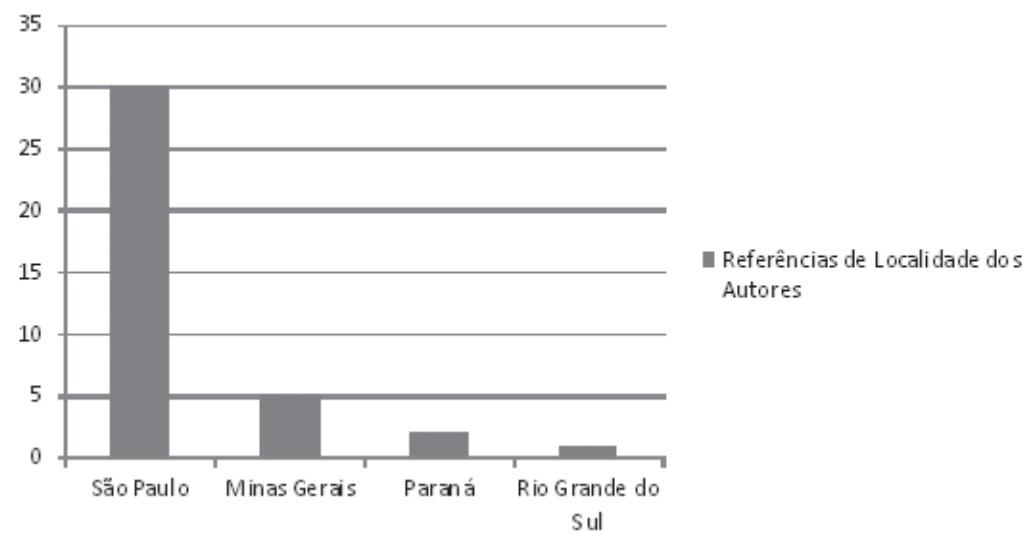

publicando livros didáticos na área de História. André Paula, Vera Lúcia Pereira, Antonio Pedro e Carla Anastácia lecionam História na UEPG, USC, PUC-SP e UFMG, respectivamente. Nelson Piletti é professor livre-docente de História da Educação aposentado da USP, Leonel Iaussu ensina Ciências Políticas também na USP e Luís César Amad Costa, Direito Comercial na FGV. Dora Schmidt leciona Metodologia e Prática do Ensino de História na UFPR. Há também a menção de trabalhos junto aos docentes, em programas de formação continuada (4), de assessoria aos órgãos públicos (4), de consultoria a empresa (1) e organização não governamental (1).

A construção formal e coerente dos procedimentos didáticos que a titulação e atuação profissional dos autores legitimam e o Manual do Professor realiza não se diferencia, portanto, daquilo que Roger Chartier qualificou de "sentido das formas". ${ }^{31}$ Trata-se do caráter de evento dos discursos, isto é, da ideia de que os textos são, mais do que os temas dos quais tratam, o resultado de uma prática. Assim, as regras que governam a produção das obras e a organização das práticas não definem apenas os padrões de incorporação das divisões da organização social na forma de representações coletivas, mas igualmente são percebidas enquanto formas

31 CHARTIER, R. O mundo como representação, op. cit., p. 186. 
GRÁFICO 3-EXERCÍCIO PROFISSIONALDECLARADO PELOS AUTORES.

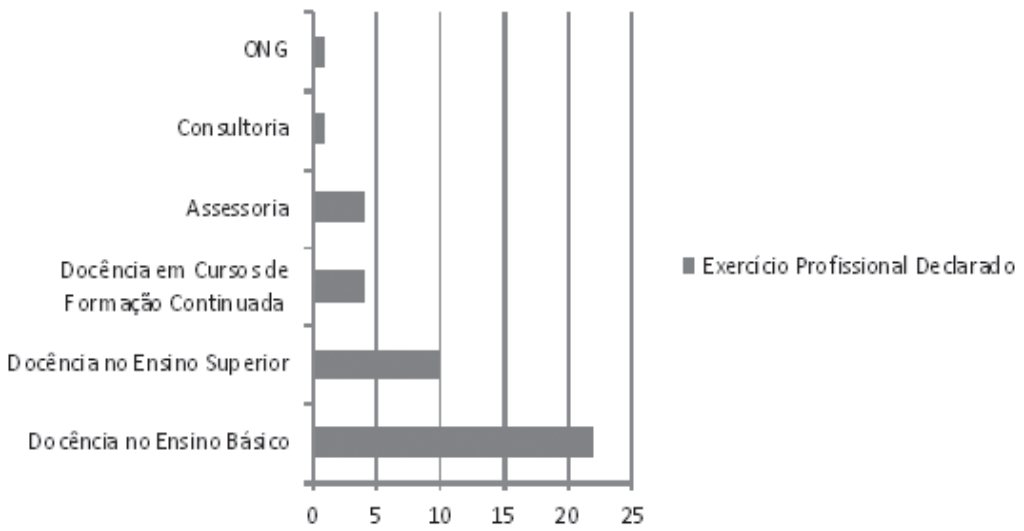

do exercício de um poder. Para Chartier, a reflexão sobre a definição das identidades sociais depende de instrumentos capazes de investir de pertinência operatória "as estratégias simbólicas que determinam posições e relações e que constroem, para cada classe, grupo ou meio, um ser-percebido constitutivo de sua identidade". ${ }^{32}$ Nesse sentido, a identificação de quem está escrevendo as obras didáticas e em quais circunstâncias o tem feito são princípios de inteligibilidade que convêm observar antes de se tentar ajustar a compreensão das representações acerca do ensino e da docência às divisões socioprofissionais do campo educacional. Se não esclarecem muito sobre o perfil da obra e da rede de compromissos e interações entre os indivíduos que as escrevem e consomem, o lugar a partir do qual se enunciam as prescrições contidas no Manual do Professor e as circunstâncias que as fazem concebíveis, comunicáveis e compreensivas, ao menos, advertem sobre a estratificação que há nos meios de expressão do tipo de discurso que se pretende analisar.

De outra parte, a competência outorgada pelas editoras e pelos avaliadores do MEC aos especialistas que publicam as obras didáticas submete o discurso sobre a prática de ensino ao que Marilena Chaú uma

33 CHAUÍ, M. Cultura e democracia. 9. ed. São Paulo: Cortez, 2001, p. 10. 
vez designou de norma restritiva do "não é qualquer um que pode dizer a qualquer outro qualquer coisa em qualquer lugar e em qualquer circunstância". ${ }^{33}$ Nesses termos, a noção de competência tem a função precisa de marcar a desigualdade entre a fala e o saber do especialista e os receptores do conhecimento. Contudo, segundo esclarece Chauí, sua eficácia social como discurso do conhecimento consiste em permitir ao não especialista a ilusão de participar do saber. Daí a elaboração de uma série de discursos segundos ou derivados parecer ser a muitos críticos uma das maneiras mais eficazes de outorgar competência aos interlocutores que puderem assimilá-los. Para Chauí, a elaboração de discursos de popularização do conhecimento serve apenas para ocultar uma desigualdade social e econômica. ${ }^{34}$

Sob o signo da organização burocrática e do mercado editorial, o Manual do Professor tanto mais reforça a ideia de competência quanto indulgentemente permite ao docente interiorizar as práticas do seu ofício, confirmando, ainda nos termos de Chaú, a legitimidade daqueles a quem a burocracia e a organização determinaram previamente como autorizados a falar. ${ }^{35}$ Em muitos sentidos, seu discurso é um derivado do conjunto de obras que referencia e indica para o professor. O Manual do Professor se passa, assim, por um guia para o trabalho do dia a dia. Sobretudo visto a partir da sua utilidade para a atualização e formação continuada do magistério e, portanto, do programa e das práticas que orienta, repousa na suspeita de os professores não terem tido formação adequada ou experiência suficiente. Conforme observa Torres, num programa de distribuição de livros didáticos formulado em função de tamanha desconfiança em relação ao professorado, em vez de o texto escolar estar a serviço do professor, ocorre o inverso: "Esse tipo de texto, embora pensado para o professor de escassa formação e experiência [...] homogeneíza os docentes e perpetua a crescente dependência do professor com relação ao livro didático, reservando-lhe um papel de simples manipulador de textos e manuais, limitando de fato sua formação e crescimento". ${ }^{36}$

A distinção que Chauí opera entre a fala e o saber do especialista e os receptores do conhecimento é de certa forma confirmada por Torres quando se reconhece o Manual do Professor como insumo de serviço. Cer- 
teau prefere pensar questões desse tipo nos termos de um arranjo feito com "autoridades fantasmadas e ausentes" e seus "aparelhos de encarnação". ${ }^{37}$ Embora também ele reconheça nos textos com estatuto de ser aplicáveis um meio para encarnar as práticas, adverte que a capacidade instrumental das operações informadoras ou reformadoras depende daqueles que farão se moverem. Contrariamente ao que o constante aperfeiçoamento da visibilidade e do reticulado dos instrumentos capazes de disciplinar não importa que grupo humano faz pensar, Certeau mostrou que os meios de fabricar autoridade e conformidade não escapam aos artifícios e subterfúgios de resistência das pessoas comuns diante dos empreendimentos que queiram desapossá-las e domesticá-las. Nesse modo de compreender a construção social do discurso competente, em vez de mera manifestação de uma exigência de interiorizar regras e normas, o Manual do Professor pode ser percebido como uma fonte de pesquisa a respeito das formas como se vêm tratando os paradigmas organizadores do discurso sobre as práticas de ensino.

Recebido em setembro de 2010. Aprovado em novembro de 2010. 